\title{
HPLC/DAD Determination of Rosmarinic Acid in Salvia officinalis: Sample Preparation Optimization by Factorial Design
}

\author{
Karina B. de Oliveira ${ }^{a}$ and Brás H. de Oliveira ${ }^{*, b}$ \\ ${ }^{a}$ Universidade Federal do Paraná, Departamento de Farmácia, \\ Av. Pref. Lothário Meissner, 632, 80210-170 Curitiba-PR, Brazil \\ ${ }^{b}$ Universidade Federal do Paraná, Departamento de Química, \\ CP19081, 81531-990 Curitiba-PR, Brazil
}

\begin{abstract}
A sálvia (Salvia officinalis) contém altos teores de ácido rosmarínico (RA), uma substância bioativa, bem como outros polifenóis. RA é facilmente oxidável e pode sofrer degradação durante a preparação da amostra para análise. O objetivo deste trabalho foi desenvolver e validar um método analítico para a determinação do RA em sálvia, usando planejamento fatorial para a otimização da preparação de amostras. Inicialmente foram determinadas as variáveis estatisticamente significativas para melhorar o rendimento da extração do RA, as quais foram depois otimizadas usando planejamento composto central (CCD). O método analítico foi validado e aplicado na análise de amostras comerciais de sálvia. O procedimento otimizado consistiu na extração com metanol aquoso (40\%) contendo uma mistura antioxidante (ácido ascórbico e ácido etileno diamino tetracético (EDTA)), com sonicação a $45^{\circ} \mathrm{C}$ por $20 \mathrm{~min}$. As amostras foram injetadas em um sistema contendo coluna $\mathrm{C}_{18}$, usando metanol (A) e ácido fosfórico aquoso $0.1 \%$ (B) em gradiente (45A:55B, 0-5 min; 80A:20B, 5-10 min) com fluxo de $1.0 \mathrm{~mL} \mathrm{~min}^{-1}$ e deteção em $330 \mathrm{~nm}$. Utilizando estas condições, as concentrações do RA foram $50 \%$ maiores quando comparadas com extração na ausência de antioxidante (recuperação de $98,94 \pm 1,07 \%$ ). Auto-oxidação do RA durante a preparação da amostra foi evitada pelo uso de antioxidante levando a resultados analíticos mais confiáveis. O método foi então aplicado na análise de amostras comerciais de sálvia.
\end{abstract}

Sage (Salvia officinalis) contains high amounts of the biologically active rosmarinic acid (RA) and other polyphenolic compounds. RA is easily oxidized, and may undergo degradation during sample preparation for analysis. The objective of this work was to develop and validate an analytical procedure for determination of RA in sage, using factorial design of experiments for optimizing sample preparation. The statistically significant variables for improving RA extraction yield were determined initially and then used in the optimization step, using central composite design (CCD). The analytical method was then fully validated, and used for the analysis of commercial samples of sage. The optimized procedure involved extraction with aqueous methanol (40\%) containing an antioxidant mixture (ascorbic acid and ethylenediaminetetraacetic acid (EDTA)), with sonication at $45{ }^{\circ} \mathrm{C}$ for $20 \mathrm{~min}$. The samples were then injected in a system containing a $\mathrm{C}_{18}$ column, using methanol (A) and $0.1 \%$ phosphoric acid in water (B) in step gradient mode (45A:55B, 0-5 min; 80A:20B, 5-10 min) with flow rate of $1.0 \mathrm{~mL} \mathrm{~min}^{-1}$ and detection at $330 \mathrm{~nm}$. Using this conditions, RA concentrations were $50 \%$ higher when compared to extractions without antioxidants $(98.94 \pm 1.07 \%$ recovery $)$. Auto-oxidation of RA during sample extraction was prevented by the use of antioxidants resulting in more reliable analytical results. The method was then used for the analysis of commercial samples of sage.

Keywords: Salvia officinallis, rosmarinic acid, HPLC, factorial design of experiments

*e-mail: bho@ufpr.br 


\section{Introduction}

Salvia officinalis L. (sage) is an aromatic plant widely used for food flavoring. Many of its pharmacological properties have been associated with polyphenolic antioxidants. ${ }^{1}$ One of them, rosmarinic acid (RA, Figure 1), has also been found in other plants. ${ }^{2}$ Important biological activities such as neuroprotective, ${ }^{3}$ antioxidant, ${ }^{4}$ antiinflammatory, ${ }^{5}$ immunomodulatory, ${ }^{6}$ photoprotection, ${ }^{7}$ and melanogenic ${ }^{8}$ have been attributed to RA. These bioactivities have prompted the development of analytical methods for the determination of RA in plant materials.

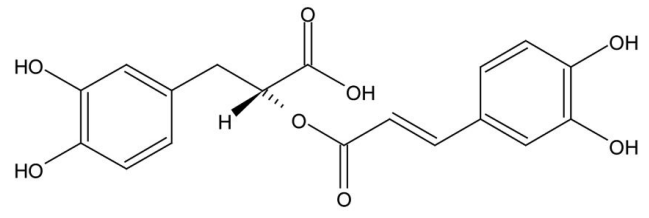

Figure 1. Structural formula of rosmarinic acid (RA).

The analysis of RA in sage and other species by high performance liquid chromatography (HPLC) has been reported in a number of occasions. ${ }^{9-13} \mathrm{~A}$ study of RA variation in sage collection describes sample preparation by solid-liquid extraction using 50\% aqueous methanol with sonication, followed by analysis using a $\mathrm{C}_{18}$ column and elution with mixtures of acetic acid, water, methanol and acetonitrile. ${ }^{14}$ However, no special attention has been given to the evaluation and prevention of possible RA auto-oxidation during the extraction procedure. The effects of variables such as solvent, temperature and time, on extraction yield are usually studied one at a time. This traditional monovariate experimental design approach is time consuming and may not lead to optimum conditions. Procedures that are more efficient are available for this purpose.

The optimization of many processes can be achieved using statistical factorial design of experiments. ${ }^{15}$ The technique is characterized by the simultaneous evaluation of multiple variables (factors) potentially significant for a given response in a process under study. The optimization can be accomplished more quickly and interactions among variables may be detected. The optimization of chromatographic separation and sample preparation have benefited from this technique. ${ }^{16}$

Considering the importance of RA and its high content in S. officinalis, our group decided to develop and validate an analytical HPLC/DAD (diode array detection) procedure for its determination in the plant. Special attention was given to sample preparation by solvent extraction presuming its possible degradation by auto-oxidation. The sample extraction was optimized using factorial design of experiments and the method was then used for the analysis of commercial samples of sage.

\section{Experimental}

Instrumentation and analytical conditions

${ }^{1} \mathrm{H}$ and ${ }^{13} \mathrm{C}$ nuclear magnetic resonance (NMR) spectra were acquired on a Bruker Avance 200 spectrometer using tetramethylsilane (TMS) as an internal standard. A Varian HP 920 series HPLC system with quaternary pump, autosampler, thermostatted column compartment and photodiode array detector (PDA) was used for analysis. Rosmarinic acid was quantified by HPLC as described previously with some modifications. ${ }^{10}$ The chromatographic analysis was performed with $\mathrm{C}_{18}$ column (Agilent Eclipse $\mathrm{C}_{18}, 150 \mathrm{~mm} \times 4.6 \mathrm{~mm} \times 5 \mu \mathrm{m}$ ) at $25^{\circ} \mathrm{C}$, using methanol (eluent $\mathrm{A}$ ) and $0.1 \%$ phosphoric acid in water (eluent B) in step gradient mode (45:55, 0-5 min; $80: 20,5-10 \mathrm{~min})$. The flow rate was $1.0 \mathrm{~mL} \mathrm{~min}{ }^{-1}$ and detection at $330 \mathrm{~nm}$. The concentration of rosmarinic acid was determined using external standard calibration. Analytical curves were constructed with five solutions of standard RA (6.25-100 $\left.\mu \mathrm{g} \mathrm{mL}^{-1}\right)$ injected at $0,7,15$ and 30 day intervals. Sample solutions were prepared using the optimized extraction procedure and analyzed at 0 , 3 and 7 day intervals. In both cases, between injections, the solutions were stored in the dark at $6{ }^{\circ} \mathrm{C}$. The data were then statistically analyzed.

\section{Plant material and rosmarinic acid isolation}

Sage leaves were purchased in a local market and identified by macro and microscopic analysis. ${ }^{17}$ Isolation of RA was carried out from hydroalcoholic extract (10 g) which was dissolved in water $(300 \mathrm{~mL})$ at $80{ }^{\circ} \mathrm{C}$. After cooling, the solution was filtered, acidified to $\mathrm{pH}$ 2-2.5 with $25 \% \mathrm{HCl}$ and centrifuged. The supernatant was then extracted with diethyl ether $(5 \times 100 \mathrm{~mL})$. The organic fractions were combined and the solvent evaporated. Portions of the extract were then fractionated in a Chromatotron (centrifugal thin-layer chromatograph) (Harrison Research Chromatotron model 7924) using silica gel rotors (Aldrich, 346446) and the elution was made with ethyl acetate/hexane/acetic acid (30:60:10). Fractions containing RA were combined, the solvent evaporated and the residue stored under nitrogen, in the dark. The isolated compound was characterized by spectroscopic methods (UV, ${ }^{1} \mathrm{H}$ and ${ }^{13} \mathrm{C}$ NMR) and its purity was also determined by HPLC/DAD. 


\section{Optimization of sample preparation}

The screening of statistically significant factors for RA extraction was made with a $2^{4}$ factorial design with duplicates (32 experiments). The four factors and their respective levels are shown in Table 1. Dried powdered plant material was sieved (310-740 $\mu \mathrm{m})$, weighed $(100 \mathrm{mg})$ and extracted with sonication with appropriate solvent $(10 \mathrm{~mL})$. The experiments with antioxidant were carried out with extracting solutions containing ascorbic acid $\left(1 \mathrm{mg} \mathrm{mL}^{-1}\right)$ and EDTA (ethylenediaminetetraacetic acid, $0.3 \mathrm{mg} \mathrm{mL}^{-1}$ ).

Table 1. Factors and respective low and high values used for screening of significant variables for extraction of rosmarinic acid from $S$. officinalis

\begin{tabular}{lcc}
\hline Factor & Low & High \\
\hline (A) Solvent (metanol / \%) & 35 & 70 \\
(B) time / min & 10 & 25 \\
(C) Temperature $/{ }^{\circ} \mathrm{C}$ & 25 & 45 \\
(D) Antioxidant & yes & no \\
\hline
\end{tabular}

The extraction optimization was carried out using two consecutive central composite design (CCD) and all experiments were carried out with added antioxidant. In the first CCD, the significant parameters determined in the screening step (solvent, time and temperature) were used. The factors and their respective levels are summarized in Table 2. In the second CCD, the temperature was fixed at $45^{\circ} \mathrm{C}$ and solvent and time were varied (Table 3 ). Solutions were filtered, diluted in 50\% methanol (1:10) and injected into the chromatographic system. The data were then statistically analyzed and plotted.

Table 2. Central composite design factors and respective values used for optimization of extraction of rosmarinic acid from S. officinalis. ( $\mathrm{n}=5$ at center point; $\alpha=1.68179$ )

\begin{tabular}{lccccc}
\hline \multirow{2}{*}{ Factor } & \multicolumn{5}{c}{ Experimental domain ${ }^{\mathrm{a}}$} \\
\cline { 2 - 6 } & $-\alpha$ & -1 & 0 & 1 & $\alpha$ \\
\hline Solvent (metanol / \%) & 39.8 & 50 & 65 & 80 & 90.2 \\
time / min & 16.6 & 20 & 25 & 30 & 33.4 \\
Temperature / ${ }^{\circ} \mathrm{C}$ & 29.9 & 35 & 42.5 & 50 & 55.1 \\
\hline
\end{tabular}

aDesign points: center $(0)$, cubic $(-1,1)$, axial $(-\alpha, \alpha)$.

\section{Final optimized extraction method}

Dried powdered $(310-740 \mu \mathrm{m})$ plant material was weighed $(100 \mathrm{mg})$ and extracted with sonication with $40 \%$ methanol in water $(10 \mathrm{~mL})$, containing ascorbic acid $\left(1 \mathrm{mg} \mathrm{mL}^{-1}\right)$ and EDTA $\left(0.3 \mathrm{mg} \mathrm{mL}^{-1}\right)$, at $45^{\circ} \mathrm{C}$ for $20 \mathrm{~min}$. Samples were then filtered, diluted (1:10) with $50 \%$ methanol in water, and analyzed.
Table 3. Central composite design factors and respective values used for optimization of extraction of rosmarinic acid from S. officinalis. ( $n=5$ at center point; $\alpha=1.68179$ )

\begin{tabular}{lccccc}
\hline \multirow{2}{*}{ Factor } & \multicolumn{5}{c}{ Experimental domain ${ }^{\mathrm{a}}$} \\
\cline { 2 - 6 } & $-\alpha$ & -1 & 0 & 1 & $\alpha$ \\
\hline Solvent (metanol /\%) & 15.9 & 20 & 30 & 40 & 44.1 \\
time / min & 17.9 & 20 & 25 & 30 & 32.1 \\
\hline
\end{tabular}

aDesign points: center $(0)$, cubic $(-1,1)$, axial $(-\alpha, \alpha)$.

\section{Stability of standard and samples solutions}

Analytical curves were constructed with five solutions of standard RA (6.25-100 $\left.\mu \mathrm{g} \mathrm{mL}^{-1}\right)$ injected at $0,7,15$ and 30 day intervals. Sample solutions were prepared using the optimized extraction procedure and analyzed at 0, 3 and 7 day intervals. In both cases, between injections, the solutions were stored in the dark at $6{ }^{\circ} \mathrm{C}$. The data were then statistically analyzed.

\section{Selectivity}

Selectivity was evaluated by the peak purity function of the chromatography software and by direct inspection of the UV spectra at upslope, apex and downslope portions of the peak of RA in HPLC-PDA chromatograms.

\section{Linearity}

Linearity was determined for standard and sample solutions. RA solutions (6.25-100 $\mu \mathrm{g} \mathrm{mL}^{-1}$ ) were prepared and injected in 3 consecutive days into the HPLC system. Plant material (80, 90, 100, 110 and $120 \mathrm{mg}$ ) was extracted as described above and analyzed. The solutions were stored in the dark at $6{ }^{\circ} \mathrm{C}$. Data were then statistically evaluated for correlation coefficient (r), coefficient of determination $\left(\mathrm{R}^{2}\right)$ and residuals of regression analysis.

\section{Accuracy}

The RA concentration was determined using an integrated calibration method. ${ }^{18}$ Standard addition calibration curve was made with plant material (100 mg) spiked with $0,100,200,300$ and $400 \mu \mathrm{L}$ of RA solution (10 $\left.\mathrm{mg} \mathrm{mL}^{-1}\right)$. After extraction as described above, the samples, with final concentrations increased by $0,10,2030$ and $40 \mu \mathrm{g} \mathrm{mL}{ }^{-1}$, were analyzed. The data were plotted in the same regular calibration graph prepared as described in the previous section. The concentration of RA was determined by extrapolating the value of the linear coefficient of the equation for spiked sample solutions into that of the standard equation. Extract samples with 80, 100 and 120\% of theoretical values were then prepared in triplicate, under the same conditions used for linearity tests. The samples were then analyzed and recovery calculated. 


\section{Precision}

Within-day precision (repeatability) was evaluated by repeated analyses of plant material $(n=6)$, and between-day precision (reproducibility) was evaluated by two analysts in two consecutive days $(n=6)$. The concentration of RA was determined and the relative standard deviation (RSD) calculated and compared.

Limits of detection and quantitation

The limits of detection and quantitation (LOD and LOQ, respectively) were calculated according to the equations $\mathrm{LOD}=3.3 \delta / \mathrm{S}, \mathrm{LOQ}=10 \delta / \mathrm{S}$, where $\delta$ is the standard deviation of responses and $\mathrm{S}$ is the slope of the analytical curve. ${ }^{19}$ Appropriate dilutions were then prepared and analyzed in order to confirm those limits.

\section{Statistical analysis}

Student's $t$-test or analyses of variance (ANOVA), followed by Tukey test where necessary, were carried out using Graph Pad-Prism 5 software. Data were expressed as the mean \pm standard deviation (SD).

\section{Results and Discussion}

\section{Rosmarinic acid isolation and characterization}

The chromatographic procedure used for RA isolation was efficient producing $450-550 \mathrm{mg}$ per $10 \mathrm{~g}$ of dry hydroethanolic extract. The product was characterized by spectrometric methods and its ${ }^{1} \mathrm{H}$ and ${ }^{13} \mathrm{C}$ NMR spectra were compared with literature data. ${ }^{20,21}$ Using HPLC/DAD analysis the purity of RA was determined as $97.25 \%$.

\section{HPLC analysis optimization}

The analysis of RA in plant materials has been described in a number of ocasions. The procedures usually involve the use of $\mathrm{C}_{18}$ columns. ${ }^{10}$ Initial attempts using Reselut column (Varian, $150 \mathrm{~mm} \times 4.6 \mathrm{~mm} \times 5 \mu \mathrm{m}$ ) were unable to provide a base-line separation. Another $\mathrm{C}_{18}$ column (Eclipse (Agilent)) with the same dimensions provided a sucessful separation of RA (Figure 2) This column was, therefore, used for method development. Mobile phase was methanol (eluent A) and $0.1 \%$ phosphoric acid in water (eluent B) in step gradient mode (45:55, 0-5 min; 80:20, 5-10 min).

\section{Optimization of sample preparation}

The sample preparation for polyphenolic analytes may require special attention due to the possible oxidation of these compounds. Solid-liquid extractions involving

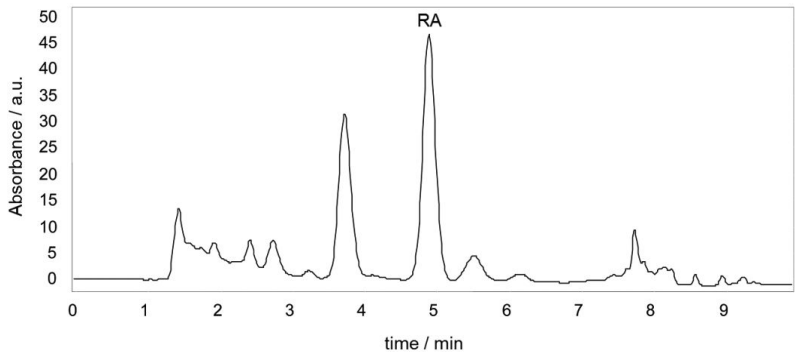

Figure 2. Chromatogram of sage extract showing RA peak.

heating and/or sonication may further increase the possibility of degradation. The study of the effect of these and other variables on extraction efficiency, one at a time, is more time consuming and may not provide adequate results because some variables may interact with each other. These interactions are not easily detected unless statistical designs of experiments are used. Statistical multivariate design of experiments usually involves an initial screening step in order to identify statistically significant factors followed by an optimization step using a surface response method. ${ }^{16}$ All factors are evaluated simultaneously and possible interactions among are detected. This two-step methodology was used for the optimization of sample preparation for RA analysis.

In the initial step, solvent (methanol, \%), time, temperature and antioxidant (with or without) were selected for initial screening of the statistically significant variables (Table 1). In order to minimize RA degradation, an antioxidant mixture containing ascorbic acid and EDTA was also tested. The results showed that all factors significantly affected RA extraction (Figure 3). The influence of the antioxidant mixture was the most significant. When ascorbic acid and EDTA are present in the extraction mixture, there is a $50 \%$ increase in the RA content of the extract, indicating that oxidation of the analyte was taking place during extraction when they are not present.

One factor may influence the effect of another and this interaction can be readily recognized in interaction graphs. They are constructed with response data from two factors and show the impact on response of one factor over the other. Different slopes (unparallel lines) indicate interaction among those factors. ${ }^{15}$ The evaluation of possible interaction among variables showed interesting results (Figure 4). The first interaction observed was between methanol concentration and temperature. At $25^{\circ} \mathrm{C}$, a higher concentration of methanol produced higher yields. At higher temperatures, however, the difference in methanol concentration resulted in smaller difference in RA extraction. The second interaction between methanol concentration and antioxidant was the most pronounced. In 


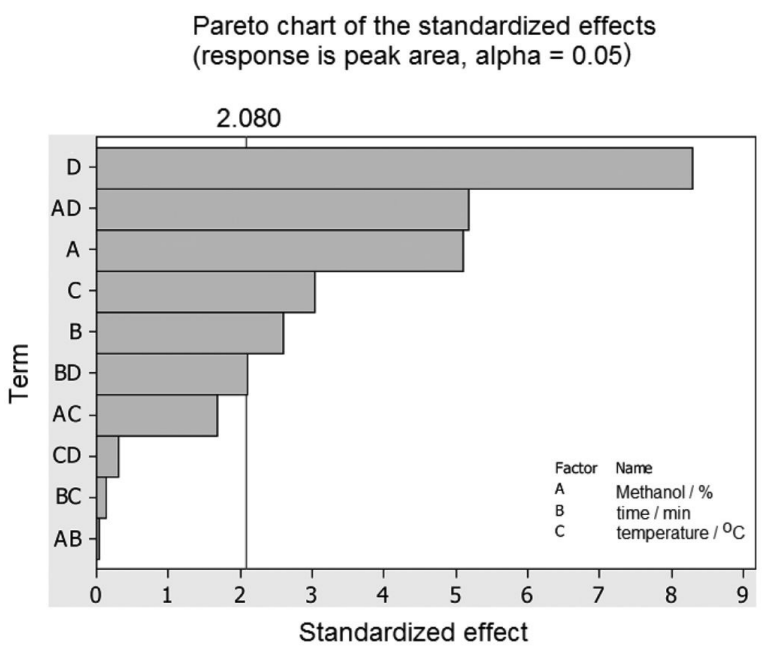

Figure 3. Pareto chart for the screening of parameters for extraction of RA from S. officinalis. Measured response was peak area.

the presence of antioxidant mixture, there was no difference in the extraction yield. When ascorbic acid and EDTA were not present in the extraction mixture, the yield was drastically reduced with smaller concentration of methanol. The third interaction was between time and antioxidant. When antioxidant was present in the extraction mixture, there was a very small difference in the yield with different extraction times. Without antioxidant, RA yields increase with time but to a smaller degree when compared with the increase in methanol concentration. All these interactions among variables would be difficult to detect by monovariate experimental designs.

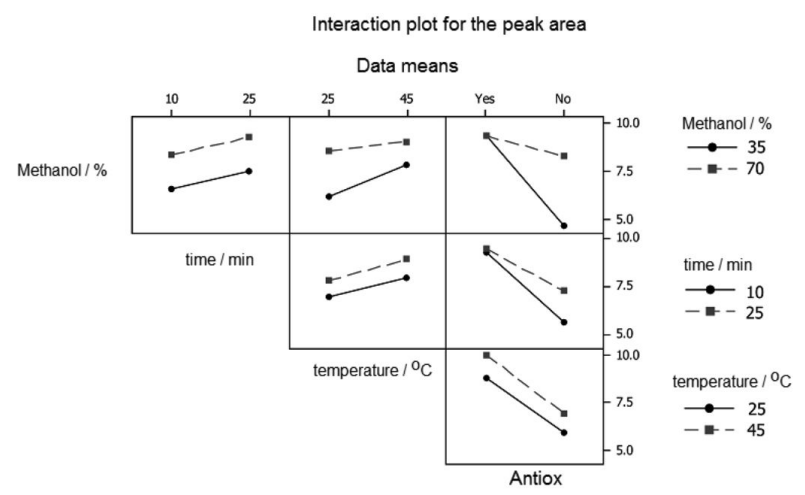

Figure 4. Interaction effect plot for the screening of parameters for extraction of RA from S. officinalis. Response is peak area ( $y$-axis).

The next step, the optimization of the variables for maximum extraction yield, was planned using CCD. Solvent, time and temperature were chosen since they were previously determined as statistically significant (Table 2). All experiments were carried out in the presence of antioxidants. Initial results showed that the highest extraction yields were obtained with temperatures above
$40{ }^{\circ} \mathrm{C}$, and methanol concentration in the range $40-50 \%$. However, as the highest extraction yield results are located at the left side of the contour map ( $40 \%$ methanol), the optimum concentration of methanol could be below $40 \%$. Another optimization step was, therefore, carried out this time keeping the temperature at $45^{\circ} \mathrm{C}$.

The results of the second optimization step (Figure 5) show that, in fact, extraction time could be reduced to less than $20 \mathrm{~min}$ as long as the methanol concentration was in the range $32.5-45 \%$. The final method, therefore, consisted of extraction of plant material with $40 \%$ methanol in water, containing ascorbic acid and EDTA, at $45{ }^{\circ} \mathrm{C}$ for $20 \mathrm{~min}$ with sonication.

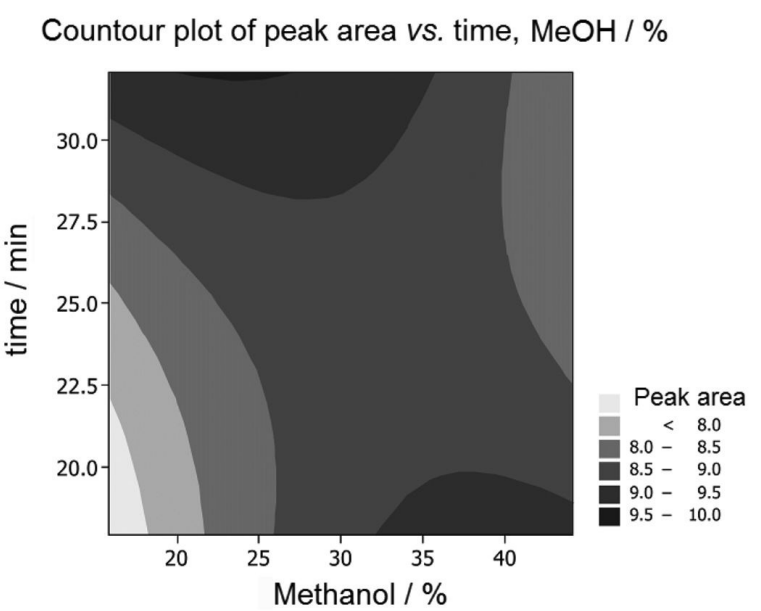

Figure 5. Contour map for the optimization of factors for RA extraction from S. officinalis. Extractions were carried out at $45^{\circ} \mathrm{C}$ in the presence of ascorbic acid and EDTA.

Method validation

After optimization of sample preparation, the analytical method was validated according to international ${ }^{22}$ and Brazilian ${ }^{23}$ guidelines. Selectivity was confirmed by the spectral purity of RA using the peak purity function of the PDA detector. The stability of RA, in standard solutions, was evaluated by comparison of five-point analytical curves obtained after storage of solutions in the dark and at $6^{\circ} \mathrm{C}$. The data for standard RA showed that the 4 curves obtained within 30 days were superimposable and linear $(\mathrm{r} \geq 0.9997$, slopes $0.5055 \pm 0.0027,0.5120 \pm 0.0040$, $0.5091 \pm 0.0069$ and $0.4998 \pm 0.0047$ at $0,7,15$ and 30 days, respectively) indicating negligible RA degradation. Results for extract solutions showed that after 3 days, there was a small, but not significant decrease in RA concentration. After 7 days, however, the decrease was significant $(6.5 \%)$. Therefore, sample extracts are stable for 3 days when stored as described. The results of other validation parameters are summarized in Table 4. 
Table 4. Method validation data for rosmarinic acid determination in S. officinallis

\begin{tabular}{|c|c|c|}
\hline & Parameter & Result \\
\hline \multirow[t]{5}{*}{ Linearity (standard) } & function & $y=0.5053 x+0.000834$ \\
\hline & $\mathrm{r}$ & 0.9999 \\
\hline & $\mathrm{R}^{2}$ & 0.9998 \\
\hline & residuals (homoscedasticity) & random distribution \\
\hline & range & $6.25-100 \mu \mathrm{g} \mathrm{mL}^{-1}$ \\
\hline \multirow[t]{5}{*}{ Linearity (extract) } & function & $y=0.4640 x+0.6512$ \\
\hline & $\mathrm{r}$ & 0.9991 \\
\hline & $\mathrm{R}^{2}$ & 0.9982 \\
\hline & residuals (homoscedasticity) & random distribution \\
\hline & range & $15.08-22.62 \mu \mathrm{g} \mathrm{mL}^{-1}$ \\
\hline \multirow[t]{2}{*}{ Precision } & intra day & $\operatorname{RSD}<3.25 \%(\mathrm{n}=6)$ \\
\hline & intermediate & $\mathrm{RSD}<4.05 \%(\mathrm{n}=12)$ \\
\hline \multirow[t]{3}{*}{ Accuracy } & recovery $80 \%$ theoretical concentration & $101.39 \pm 1.31 \%(\mathrm{n}=3)$ \\
\hline & recovery $100 \%$ theoretical concentration & $98.94 \pm 1.07 \%(\mathrm{n}=3)$ \\
\hline & recovery $120 \%$ theoretical concentration & $98.50 \pm 1.84 \%(\mathrm{n}=3)$ \\
\hline Limit of detection (LOD) & & $0.005 \mu \mathrm{g} \mathrm{mL} \mathrm{m}^{-1}$ \\
\hline Limit of quantitation (LOQ) & & $0.017 \mu \mathrm{g} \mathrm{mL}^{-1}$ \\
\hline
\end{tabular}

RSD: relative standard deviation; r: correlation coefficient; $\mathrm{R}^{2}$ : coefficient of determination.

Linearity was evaluated for both standard RA and extract solutions. The analytical curve obtained from standard RA (6.25-100 $\left.\mu \mathrm{g} \mathrm{mL}^{-1}\right)$ was linear and residual plots indicated random distribution (homoscedasticity) ${ }^{24}$ without bias or outliers. In order to detect possible matrix effects, calibration curves were also prepared with sample extracts with RA concentration in the $15.08-22.62 \mu \mathrm{g} \mathrm{mL}$ range. Again, a good linearity was obtained showing insignificant interference from matrix components.

The evaluation of accuracy in plant material analysis is more difficult to accomplish because there is no sample matrix free from the analyte. In order to overcome this drawback, the RA concentration was determined using the integrated calibration method. This procedure involves the combination of the regular calibration plot with that prepared by the method of standard addition in which increased amounts of standard analyte is added to sample solutions (Figure 6). ${ }^{18}$ The RA concentration in the sample was determined by extrapolating the value of the linear coefficient of the equation for spiked sample solutions into that of the standard equation (dashed lines in Figure 6). After correction for dilution and sample size, the concentration of $18.85 \mathrm{mg} \mathrm{g}^{-1}$ was found. Accuracy was finally determined after analysis of sample solutions containing 80,100 and $120 \%$ of theoretical RA values, in triplicate. The results are shown in Table 4.

The matrix effect could also be estimated from the slope ratio (SR) of both curves (Figure 6). It was calculated by

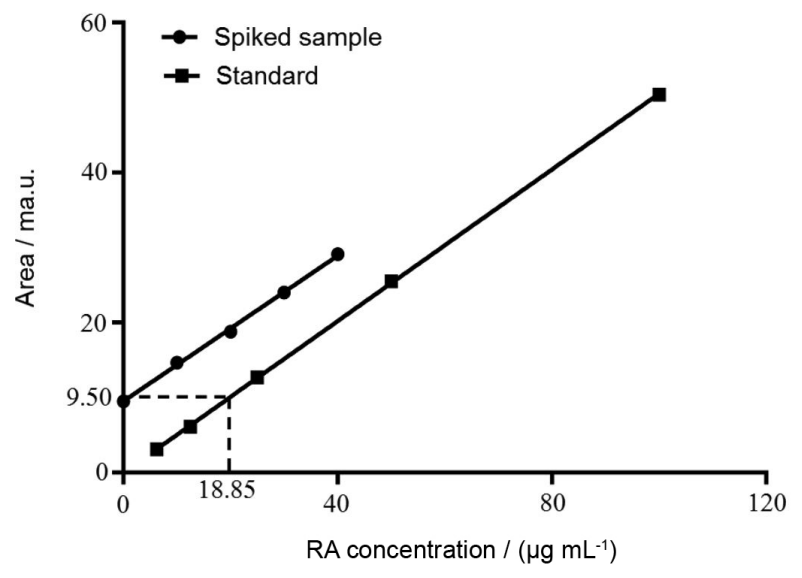

Figure 6. Calibration curves prepared with solutions of RA standard and with extract samples spiked with increasing amounts of RA followed by preparation.

$\mathrm{SR}=\mathrm{S}_{1} / \mathrm{S}_{2}$, where $\mathrm{S}_{1}$ and $\mathrm{S}_{2}$ are the slopes for the plots of spiked extract samples and standard RA, respectively. The result (0.96) indicated a very small influence of matrix effect. ${ }^{18}$

\section{Commercial sample analysis}

The optimized method was then used for the analysis of two commercial samples of sage. The results $\left(5.07 \pm 0.71\right.$ and $\left.20.70 \pm 0.29 \mathrm{mg} \mathrm{g}^{-1}, \mathrm{n}=3\right)$ confirmed the precision of the method and showed the considerable variability in RA concentration in commercial sage samples. 
This variability, which depends on plant source and many other factors, justifies the need for determination of active components in medicinal plants.

\section{Conclusions}

Our results showed that the determination of rosmarinic acid from S. officinallis is severely affected by autooxidation of that analyte unless preventive measures are taken during extraction. Our results showed that the concentration of RA in extracts were $50 \%$ higher when antioxidants were added to extraction solvent. The protection of the analyte against degradation provides more accurate analytical results. The variability in RA contents found in commercial S. officinallis samples may result from many factors including seasonal and geographic influences.

\section{Supplementary Information}

The ${ }^{1} \mathrm{H}$ NMR and ${ }^{13} \mathrm{C}$ NMR spectra, HPLC/DAD chromatogram of RA (and corresponding UV spectrum), as well statistical plots (the main effects, contour plots of preliminary extraction optimization, residuals of linear regression, stability of calibration solutions) are available free of charge at http://jbcs.org.br as a PDF file.

\section{Acknowledgments}

The financial support of Coordenação de Aperfeiçoamento de Pessoal de Nível Superior (CAPES, Ministry of Education, Brazil) is greatly acknowledged.

\section{Reference}

1. Lu, Y. R.; Foo, L. Y.; Phytochemistry 2002, 59, 117.

2. Petersen, M.; Simmonds, M. S. J.; Phytochemistry 2003, 62, 121.

3. Iuvone, T.; De Filippis, D.; Esposito, G.; D'Amico, A.; Izzo, A. A.; J. Pharmacol. Exp. Ther. 2006, 317, 1143.

4. Zheng, W.; Wang, S. Y.; J. Agric. Food Chem. 2001, 49, 5165.

5. Sahu, A.; Rawal, N.; Pangburn, M. K.; Biochem. Pharmacol. 1999, 57, 1439.

6. Kang, M. A.; Yun, S. Y.; Won, J. W.; Blood 2003, 101, 3534.
7. Sanchez-Campillo, M.; Gabaldon, J. A.; Castillo, J.; Benavente-Garcia, O.; Del Bano, M. J.; Alcaraz, M.; Vicente, V.; Alvarez, N.; Lozano, J. A.; Food Chem. Toxicol. 2009, 47, 386.

8. Lee, J.; Kim, Y. S.; Park, D.; Biochem. Pharmacol. 2007, 74, 960.

9. Bonoli, M.; Pelillo, M.; Lercker, G.; Chromatographia 2003, 57,505 .

10. Wang, H. F.; Provan, G. J.; Helliwell, K.; Food Chem. 2004, 87, 307.

11. Bandoniene, D.; Murkovic, M.; Venskutonis, P. R.; J. Chromatogr. Sci. 2005, 43, 372.

12. Troncoso, N.; Sierra, H.; Carvajal, L.; Delpiano, P.; Gunther, G.; J. Chromatogr., A 2005, 1100, 20.

13. Xu, J. Z.; Shen, J.; Cheng, Y. Y.; Qu, H. B.; J. Zhejiang Univ. Sci. B 2008, 9, 728.

14. Lamien-Meda, A.; Nell, M.; Lohwasser, U.; Börner, A.; Franz, C.; Novak, J.; J. Agric. Food Chem. 2010, 58, 3813.

15. Montgomery, D. C.; Design and Analysis of Experiments, $5^{\text {th }}$ ed.; Wiley: New York, USA, 2001.

16. Ferreira, S. L. C.; Bruns, R. E.; da Silva, E. G. P.; dos Santos, W. N. L.; Quintella, C. M.; David, J. M.; de Andrade, J. B.; Breitkreitz, M. C.; Jardim, I. C. S. F.; Neto, B. B.; J. Chromatogr., A 2007, 1158, 2.

17. Wichtl, M.; Herbal Drugs and Phytopharmaceuticals, $3^{\text {rd }}$ ed.; Medpharm Scientific Publishers: Stuttgart, Germany, 2004.

18. Miller, J. N.; Analyst 1991, 116, 3.

19. Miller, J. C.; Miller, J. N.; Statistics for Analytical Chemistry, $2^{\text {nd }}$ ed.; Ellis Horwood: Chichester, UK, 1988.

20. Kelley, C. J.; Mahajan, J. R.; Brooks, L. C.; Neubert, L. A.; Breneman, W. R.; Carmack, M.; J. Org. Chem. 1975, 40, 1804.

21. Kelley, C. J.; Harruff, R. C.; Carmack, M.; J. Org. Chem. 1976, $41,449$.

22. International Conference on Hormonisation (ICH) of Technical Requirements for Registration of Pharmaceuticals for Human Use, Q2(R 1), Validation of Analytical Procedures, Methodology, 1996, London, Complementary Guideline on Methodology incorporated in November 2005.

23. Agência Nacional de Vigilância Sanitária (ANVISA); Guia para Validação se Métodos Analíticos e Bioanalíticos, Resolução RE No. 899, Anvisa, Brasil, 2003.

24. Analytical Methods Committee; Analyst 1994, 119, 2363.

Submitted: December 9, 2011

Published online: February 7, 2013 